\title{
Learning and Developing Followership
}

\author{
Colette Hoption \\ Albers School of Business \& Economics \\ Seattle University \\ Department of Management \\ Albers School of Business \& Economics \\ hoptionc@seattleu.edu
}

\begin{abstract}
Followership has been recognized as an essential component of leadership studies as evidenced by growth of research within this area. To keep pace with the growth of this research, it is time to bring followership into the leadership classroom. This paper proposes a case-based exercise with two main learning objectives: (1) to help students broaden their perceptions about followership, and (2) to promote followership behaviors that actively contribute to organizations. This exercise includes large group discussion, peer coaching, and individual work to facilitate these endeavors. The paper concludes with suggested methods for assessment that include both self- and peerratings, as well as open-ended reflection.
\end{abstract}

\section{Introduction}

Followership is consistently identified as an emergent and important area in the extant leadership literature. There are calls from practitioners for effective followers (see Kellerman, 2008), a need to mitigate followers' risks to negative leadership (such as pseudotransformational leadership; e.g., Bass \& Steidlmeier, 1999), a desire to more faithfully study the long-held belief that followers are partners in leadership [see for example Leader-Member Exchange (LMX) theory; e.g., Graen \& Uhl-Bien, 1995], and opportunities to account for bidirectional influence between leaders and followers given statistical advancements (Kenny, Kashy, \& Cook, 2006). As followership research burgeons, one might anticipate a growth within the rigor and frequency of discussions about followership in the leadership classroom.

Unfortunately, a rigorous discussion about the interplay between leadership and followership is difficult for two main reasons: negative stereotypes surrounding followers (see Baker, 2007) and predominant leadership frameworks that reinforce followers' negative stereotypes (e.g., Klein \& House, 1995). These reasons limit students from appreciating the possibilities for followers to influence their leaders and their organizations. They also undermine the tenets of positive forms of leadership that require leaders to believe in their followers (e.g., Bass, 1998). In response, the goal of this article is to describe a teaching tool that engages students in a thoughtful discussion about followership. The teaching tool has two learning objectives:

Learning Objective 1: Broadening students' understanding of followers and followership.

Learning Objective 2: Enabling students to enact followership behaviors that contribute to leadership and organizations. 
To introduce the importance of these learning objectives, first, I describe the nature of follower stereotypes and, then present a contrasting view of followership. Thereafter, I present a three-part classroom exercise: Part 1 initiates a discussion on followership that combats predominant stereotypes about followers; Part 2 inspires ideas for how followers can be influential in organizations; and Part 3 offers students an opportunity to practice influential followership behaviors. Altogether, the exercise not only impresses upon students the value of followers, but also helps students become valuable followers.

\section{Followership Connotations}

Followers are often associated with negative characteristics including passivity and dependence (e.g., Baker, 2007; Raffo, 2013). They have been referred to as "drab powerless masses" (Burns, 1978) and "sheep" (Dixon \& Westbrook, 2003). Therefore, it is not surprising that, when learning about leadership, the topic of followership may never arise; and if it does, students' responses reflect those negative stereotypes. Lest one assumes that such stereotypes are mainly propagated by students with limited work experience, even in professional populations, typical follower traits include qualities like "slow" and "easily influenced" (Sy, 2010).

Furthermore, predominant leadership theories reinforce follower passivity and inferiority to leaders. Charismatic leadership theories, for example, cast followers as recipients of leadership awaiting leader influence (e.g., Klein \& House, 1995). Even leadership theories that describe followers as active participants in leadership (e.g., LMX) have been criticized for focusing empirical investigations on leaders' actions in determining the nature of the leaderfollower relationship (see Dvir \& Shamir, 2003). As a result, we know much more about leader influence on the leader-follower relationship; and in the absence of knowledge about follower influence, leaders are poised to receive credit for forming high-quality leader-follower relationships.

If unaddressed, negative follower connotations can hinder positive leadership and disadvantage individuals in non-leadership positions. Positive leadership often includes developing followers into leaders (e.g., Bass, 1998) and working closely with followers to achieve goals (e.g., Stone, Russell, \& Patterson, 2004). Leaders who espouse negative follower connotations would have difficulty transforming and working alongside followers. As those leaders are a liability to their organizations' human capital and development, it is necessary that followership education be a part of developing individuals' leadership skills (see Johnson, 2009).

With regard to disadvantaging individuals in non-leadership positions, there is evidence that followers in organizations acknowledge negative stereotypes as part of their identities (Carsten, Uhl-Bien, West, Patera, \& McGregor, 2010). Given the empirical studies linking selfesteem (e.g., Chang, Ferris, Johnson, Rosen \& Tan, 2012), self-efficacy (e.g., Sitzmann \& Yeo, 2013), and positive affect (e.g., Lyubomirsky, King, \& Diener, 2005) to work performance, as well as evidence for stereotype-threat (e.g., Hoption, Christie, \& Barling, 2012), awareness of and identification with negative follower stereotypes likely impedes effectiveness. Therefore, followership education should work towards countering negative follower stereotypes and preparing students to excel in follower roles.

In particular, there is growing interest in active followership. While an agreed-upon definition of active followership has yet to emerge, Howell and Shamir (2005) capture its 
essence in recognizing followers" "active role in constructing the leadership relationship, empowering the leader and influencing his or her behavior, and ultimately determining the consequences of the leadership relationship" (p. 97). Scholars include helping (but not serving) leaders, questioning leader assumptions, taking initiative, granting legitimacy to leaders, and spreading enthusiasm to coworkers as examples of active followership behaviors (e.g., Baker, 2007; Chaleff, 2008; Howell \& Méndez, 2008; Kelley, 1992). Essentially, active followership counters negative follower stereotypes. And so, expanding students' understanding of followership to encompass active followership would facilitate both learning objectives: broadening their understanding of followership to include characteristics and behaviors that exemplify strength and value; and seeing the potential to participate in leadership when in follower positions.

To recap, teaching followership addresses four areas of interest: (1) reflecting current trends in leadership research in the leadership classroom; (2) challenging predominant negative follower stereotypes that limit understanding of follower capabilities and value in organizations; (3) enabling students to see and enact upon the possibilities to overcome negative follower stereotypes and exert influence on leadership and organizations; and (4) redressing the dissonance between enacting positive leadership and awareness of negative follower stereotypes.

\section{The Case for Followership}

To achieve both learning objectives, I propose a case-based exercise appropriate for undergraduate and graduate classes. Case-teaching is an effective way to develop problemsolving skills, creativity, and perspective-taking at all levels (Greenhalgh, 2007), but this teaching tool could emphasize different lessons in undergraduate and graduate classes to reflect the fact that graduate and undergraduate students are at different stages in their careers. For example, in an undergraduate class, this exercise could help students extend leadership paradigms described in their textbooks (e.g., how do various leadership frameworks account for follower influence?). In a graduate class, this exercise could help students confront their assumptions about followers, and identify the ways that their past and current organizational cultures reinforce those assumptions. This case is adapted from O'Hara's (1999) article, "Trade Secrets," published in Maclean's.

Bill Reid was a Native Canadian artist whose works of art included the "The Spirit of Haida Gwaii: The Jade Canoe" and "The Raven and the First Men." In addition to his carvings, jewelry, and sculptures, Reid's legacy also included his investment in then-upcoming artists like Don Yeomans, Sharon Hitchcock, George Rammell and Jim Hart. He opened his studio to them and they became his apprentices. His dedication to helping young Native artists in particular, and exposing Native art to the masses made him a prominent political figure and cultural icon.

On March 13 1998, Reid lost his battle with Parkinson's disease. After his passing, details of Reid's work style and treatment of his apprentices were magnified in the media, revealing stories about his philandering, substance abuse, and duplicitous nature - all of which compromised the professional working environment. For example, Hitchcock attested to Reid's drunken state while overseeing her work on the famous "Lootaas" canoe, as well her frequent trips to a liquor store to oblige his habit. Both Rammell and Hart noted Reid's long, unexplained absences hindering them from completing projects. The apprentices were also disheartened 
because they were never formally recognized for their involvement on Reid's projects and the monetary compensation that they received was minimal. There was even speculation that Reid omitted footage of his apprentices in video productions which featured his career and work. The lack of recognition was particularly injurious because Reid's debilitating disease limited his fine motor skills, and so many of his works would never have been realized if it were not for his apprentices. Looking back on their time with Reid, many joked that they were his "slaves."

There are three main advantages to using this case. First, it is based on a real-life situation. For students who already know of Reid and/or have seen his work, the story provides a glimpse of what occurred behind-the-scenes. The case also captures the complexity of leaderfollower relationships including 'ownership' of leader-follower output, and the reality that most leaders are not 'all good' or 'all bad'. Indeed, in spite of O'Hara's article, Reid's ability to clearly communicate his visions to others, connect his apprentices to the art community, and acquire new projects to sustain his career cannot be denied. The case is also assuring for students who struggle to find real-life examples of followers' value in organizations. Second, it is appropriate to show pictures of Reid's artwork to engage students visually, and emphasize the fine motor skills necessary to complete each detailed piece. Third, there is potential to use this case to foray into related topics such as work-life spillover, employee well-being, young workers, and workplace aggression.

Part 1: The Follower Perspective (approximately 10 minutes)

Large classroom discussion begins with two consecutive questions, "Why do you think the followers/apprentices continued to work for Reid?" and "What motivations would they have to stop working for Reid?" These questions require perspective-taking. Examples of the types of responses students might offer to the first question are: "For his networks" and "To learn from his expertise." Examples of responses students might offer to the second question include "To improve their well-being" and "To send the message that they deserve better." By the end of Part 1, students will be pressed to confront the impression that followers are "drab masses" because the answers to both questions demonstrate the diversity in follower motivations.

Part 2: Possible Courses of Action for Followers (approximately 20 minutes)

In Part 2 of the exercise, group discussion is initiated by asking, "What would you do if you were one of the followers/apprentices?" This question requires students to brainstorm strategies for coping with, confronting, and changing suboptimal leadership, thus revealing possible opportunities to exert their influence. Student responses may include "Rally the other apprentices to talk to Reid with me so that we can change things," "Continue to work, but halfheartedly," "Destroy all the art to spite Reid," and "Do nothing." One goal of Part 2 is for students to see that followers have choices in how they proceed. Students are thus, pressed to concede that followers are not definitively passive and powerless, as their stereotype suggests.

A second goal of Part 2 is to link courses of action with follower motivations, i.e., connect Parts 1 and 2. By doing so, students will see that stereotypical, passive followership behaviors (e.g., "do nothing") have less potential to satisfy follower interests than other, more active strategies (e.g., "forming a support group with other apprentices," "talking with Reid about one's dissatisfaction"). I would connect Parts 1 and 2 visually for students by recording responses to Part 2 on a board separated along two axes: the degree to which a course of action is 
motivated to satisfy one's own interests (e.g., improving well-being, being able to create art; $\mathrm{x}$ axis), and the degree to which a course of action is motivated to satisfy others' interests (e.g., the well-being of the other apprentices and Reid; y-axis). [The board design is based on a popular conflict-management-styles diagram in management textbooks (e.g., Schermerhorn, 2011) and therefore, should be familiar to many students.] Reflecting on the impact one's actions could have on others' interests (i.e., y-axis) showcases the different ways in which a follower/apprentice has the potential to exert influence. I would engage in a large group discussion to decide where possible courses of action should lie on the diagram and as a result, we would revisit the motivations discussed in Part 1.

While Parts 1 and 2 push students to acknowledge the diversity in follower motivations and articulate possible follower behaviors to improve, cope with, or exit their situations, there is also an opportunity for students to engage in their own active followership development using this exercise. More specifically, to facilitate students' enactment of followership behaviors that not only counter negative follower stereotypes, but also demonstrate power and influence, it is necessary to focus on strategies that satisfy one's interests and those of others. In terms of the board diagram, such strategies would reside in the upper-right-hand corner. Those strategies are active followership behaviors: actions that positively influence how followers are led and contribute to leadership and organizational success.

Part 3: Enacting Followership (approximately 60 minutes)

Even if students have challenged their assumptions about followers and have learned that followers can be influential, it is unknown if students will enact influential followership behaviors. Indeed, Gentile (2010; 2011) argued that it is commonplace for classroom discussions to focus on what constitutes positive organizational behaviors, but it is rare to devote class time to practicing those behaviors. Consequently, Gentile developed the Giving Voice to Values (GVV) business curriculum which is available on Babson College's website. The GVV curriculum assumes that students want to act consistent with what they believe to be the 'right thing to do', but they need scripts and skill-building lessons to increase their confidence to act accordingly. GVV has been used in executive, graduate and undergraduate classrooms internationally, and most especially in business ethics classes (Gentile, 2012). Part 3 of this exercise is modeled after the GVV business curriculum.

GVV is relevant to the leadership classroom because followership education faces a similar situation to that of business ethics education: students learn that followers can contribute to leadership and organizations, but they lack experience and practice at applying those behaviors. To illustrate this point and transition into Part 3, I would ask students to describe challenges that they face when occupying follower roles, and I would draw two conclusions from the discussion: (1) although we might not find ourselves in the same position as Reid's apprentices, we can all relate to being followers and (2) effective followership requires practice. To that end, Part 3 provides students with the opportunity to develop and practice effective followership by provoking further thought on the strategies (from Part 2) listed in the upper right-hand corner of the board. Part 3 adapts the foundational activities in GVV to help students create, refine and practice dialogues that reflect active followership. (The GVV curriculum refers to such dialogues as scripts.) 
Part 3 would begin with the question of how to enact one of the solutions in the upper right-hand corner of the board. An introduction to Part 3 could be, "If you decided to talk to Reid about his behavior so as to improve the working conditions and thereby, increase productivity, what challenges might you face and how would you deal with them?" Students would work individually on identifying potential challenges and creating strategies to tackle those challenges.

After reflecting upon expected difficulties and solutions, students would craft a dialogue of what they want to say and how they would say it. I would initiate this new phase in the exercise like so: "Now that you have identified some of the challenges you might face, as well as the ways you could address those challenges, compose a script of how you would talk to Reid. Include any advance preparation you might do and/or behavioral cues you would enact." GVV also encourages peer coaching. Peer coaching entails students helping each other refine their scripts to increase persuasiveness. (I would provide students with the GVV instructional document on peer coaching available on Babson College's website.)

Altogether, the exercises of perspective-taking, brainstorming solutions, and developing a personalized strategy for active followership ensures that students engage in the mental practice of using their knowledge about followership, as well as the physical practice of performing their desired followership behaviors. As such, this teaching tool is consistent with the Kolb (1984) model of experiential learning wherein intellectual reflection/analysis and action/experimentation are necessary to create knowledge. Moreover, there is empirical evidence for the effectiveness in engaging in both mental and physical practice to aid performance (e.g., Grouios, 1992). In light of the conceptual and empirical evidence, I am confident that this case-based exercise can develop active followership.

\section{Leadership Development}

It is noteworthy that even though this exercise was generated primarily for the purpose of appreciating and developing followership, having students explore the apprentice's perspective facilitates students' leader development too. As argued by Holt and Marques (2012), the ability to understand others' feelings through verbal and nonverbal cues is necessary for modern-day leadership. Further, empirical studies have noted the positive association between perspectivetaking and effective leadership, suggesting that understanding followers' perspectives augments positive leadership (e.g., Gregory, Moates, \& Gregory, 2011).

Moreover, exposing students to positive follower qualities should help them build respect and rapport with subordinates in the workplace. In a sample of employed leaders from a variety of industries, the quality of leader-follower relationships was related to the extent to which leaders associated followers with positive traits (e.g., team player, hardworking; Sy, 2010). Sy (2010) argued that leaders' impressions of followers functioned as performance expectations, and others have established empirical links between leader expectations to employee engagement and performance (e.g., Bezuijen, van den Berg, van Dam, \& Thierry, 2006; Kierein, \& Gold, 2000; McNatt, 2000). Those studies argue that organizations benefit from leaders' genuine beliefs in followers' potential because those beliefs are expressed through actions that support and motivate followers to achieve their potential. It appears that learning about (active) followership is relevant for both leaders and non-leaders. 


\section{Measuring Outcomes}

We could assess the effectiveness of this classroom exercise in a number of ways. First, we could administer Sy's (2010) implicit followership theories questionnaire before and after the exercise to record how students' thoughts about followership have changed. Sy's scale includes positive followership traits (e.g., industriousness), and respondents record the degree to which they associate those traits with followership. I expect that the associations will be strengthened after the exercise. Students' reports on their peers' followership before and after completing the exercise are a second way to document outcomes of this exercise. I expect that students' positive followership behaviors would increase after completing the classroom exercise. Third, it would be meaningful to document behavioral impact beyond the classroom. Students could reflect on their interactions at work, in student clubs, sports teams, etc. to gain insight into the ways that their behaviors have changed when in leadership roles and non-leadership roles. Collectively, these assessments would capture students' mental and physical learning about followership.

\section{Conclusion}

As leadership studies have recognized the need for followership research, the next step is to bring followership into the leadership classroom. The case-based exercise described in this article facilitates discussion about followership and followership development in students. Additionally, through perspective-taking and broadening one's expectations about followership, this exercise also enhances students' leader development. As leadership studies have embraced the fact that there is no leadership without followership (e.g., Hollander, 1995), it is fitting that this exercise is relevant to both leadership and followership education.

\section{References}

Baker, S. D. (2007). Followership: The theoretical foundation of a contemporary construct. Journal of Leadership \& Organizational Studies, 14, 50 - 60.

Bass, B. M., \& Steidlmeier, P. (1999). Ethics, character, and authentic transformational leadership behavior. Leadership Quarterly, 10, 181 - 217.

Bezuijen, X. M., van den Berg, P. T., van Dam, K., \& Thierry, H. (2006). Pygmalion and employee learning: The role of leader behaviors. Journal of Management,35, 1258 - 1267.

Burns, J. M. (1978). Leadership. New York, NY: Harper \& Row.

Carsten, M. K., Uhl-Bien, M., West, B. J., Patera, J. L., \& McGregor, R. (2010). Exploring social constructions of followership: A qualitative study. Leadership Quarterly, 21, 543 - 562.

Chaleff, I. (2008). Creating new ways of following. In R. Riggio, I. Chaleff \& J. LipmanBlument (Eds.), The Art of Followership: How Great Followers Create Great Leaders and Organizations (pp. 67 - 87). San Francisco, CA: Jossey-Bass.

Chaleff, I. (1995). The courageous follower: Standing up to and for our leaders. San Francisco, CA: Berrett-Koehler. 
Chang, C., Ferris, D. L., Johnson, R. E., Rosen, C. C., \& Tan, J. A. (2012). Core selfevaluations: A review and evaluation of the literature. Journal of Management, 38, 81 - 128.

Dixon, G., \& Westbrook, J. (2003). Followers revealed. Engineering Management Journal, 15, $19-25$.

Dvir, T., \& Shamir, B. (2003). Follower developmental characteristics as predicting transformational leadership: A longitudinal field study. Leadership Quarterly, 14, 327 - 344.

Gentile, M. C. (2011). A faculty forum on Giving Voice to Values: Faculty perspectives on the uses of this pedagogy and curriculum for values-driven leadership. Journal of Business Ethics Education, 8, 305 - 307.

Gentile, M. C. (2012). Values-driven leadership development: Where we have been and where we could go. Organization Management Jouirnal, 9, 188 - 196.

Graen, G. B., \& Uhl-Bien, M. (1995). Relations-based approach to leadership: Development of leader-member exchange (LMX theory) over 25 years: Applying a multi-level multi-domain perspective. Leadership Quarterly, 6, 219-247.

Greenhalgh, A. M. (2007). Case method teaching as science and art: A metaphoric approach and curricular application. Journal of Management Education, 31, 181 - 194.

Gregory, B. T., Moates, K. N., \& Gregory, S. T. (2011). An exploration of perspective taking as an antecedent of transformational leadership behavior. Leadership \& Organization Development Journal, 32, 807 - 816.

Grouios, G. (1992). Mental practice: A review. Journal of Sport Behavior, 15, 42 - 59.

Holt, S., \& Marques, J. (2012). Empathy in leadership: Appropriate or misplaced? An empirical study on a topic that is asking for attention. Journal of Business Ethics, 105, 95 - 105.

Hollander, E. P. (1995). Ethical challenges in the leader-follower relationship. Business Ethics Quarterly, 5, $55-65$.

Hoption, C., Christie, A., \& Barling, J. (2012). Submitting to the follower label: Followership, positive affect, and extra-role behaviors. Zeitschrift fur Psychologie, 220, 221 - 230.

Howell, J., \& Méndez, M. (2008). Three perspectives on followership. In R. Riggio, I. Chaleff \& J. Lipman-Blument (Eds.), The Art of Followership: How Great Followers Create Great Leaders and Organizations (pp. 25 - 39). San Francisco, CA: Jossey-Bass.

Howell, J. M., \& Shamir, B. (2005). The role of followers in the charismatic leadership process: Relationships and their consequences. Academy of Management Review, 30, $96-112$.

Johnson, C. E. (2009). Introducing followership into the leadership classroom: An integrative approach. Journal of Leadership Education, 8, 20 - 30. 
Kellerman, B. (2008). Followership: How followers are creating change and changing leaders. Boston, MA: Harvard Business Press.

Kenny, D. A., Kashy, D. A., \& Cook, W. L. (2006). Dyadic Data Analysis. New York, NY: Guilford.

Kierein, N. M., \& Gold, M. A. (2000). Pygmalion in work organizations: A meta-analysis. Journal of Organizational Behavior, 21, 913 - 928.

Klein, K. J., \& House, R. J. (1995). On fire: Charismatic leadership and levels of analysis. Leadership Quarterly, 6, 183 - 198.

Kolb, D. A. (1984). Experiential learning: Experience as the source of learning and development. Englewood Cliffs, NJ: Prentice Hall.

Lyubomirsky, S., King, L., \& Diener, E. (2005). The benefits of frequent positive affect: Does happiness lead to success? Psychological Bulletin, 131, 803 - 855.

McNatt, D. B. (2000). Ancient Pygmalion joins contemporary management: A meta-analysis of the result. Journal of Applied Psychology, 85, 314 - 322.

O'Hara, J. (1999). Trade secrets. Maclean's, 112 (42), p. 20 - 29.

Raffo, D. M. (2013). Teaching followership in leadership education. Journal of Leadership Education, 12, $262-272$.

Schermerhorn, J. R. Jr. (2011). Management 11e. Hoboken, NJ: Wiley \& Sons.

Stone, A. G., Russell, R. F., \& Patterson, K. (2004). Transformational versus servant leadership: A difference in leader focus. Leadership and Organization Development Journal, $25,349-361$.

Sy, T. (2010). What do you think of followers? Examining the content, structure, and consequences of implicit followership theories. Organizational Behavior and Human Decision Processes, 113, 73 - 84.

\section{Author Biography}

Colette Hoption, Ph.D. is Assistant Professor of Management in the Albers School of Business and Economics at Seattle University in Seattle, Washington. Her research interests include followership (e.g., what it means to be an 'effective' follower), transformational leadership, negative and non-leadership, and leadership development. Colette received her doctorate in Management from Queen's University in Kingston, Ontario, Canada. 